\title{
"It is judgment by the people that have meant something to me that hurts the most": Inter-discursive evidence synthesis incorporates the lived experience of adolescent mothers
}

Anna Dion ( $\square$ anna.dion@mail.mcgill.ca )

McGill University Faculty of Medicine https://orcid.org/0000-0003-2122-222X

\section{Aime Klevor}

Peer Researcher

\section{Amy Nakajima}

Bruyere Centre for Continuing Care

Neil Andersson

McGill University

\section{Research article}

Keywords: adolescent perinatal health, pregnancy, evidence synthesis, participatory research, stigma, patient engagement, patient-oriented research

Posted Date: August 15th, 2019

DOI: https://doi.org/10.21203/rs.2.12956/v1

License: (c) (i) This work is licensed under a Creative Commons Attribution 4.0 International License. Read Full License 


\section{Abstract}

Background Evidence synthesis without meaningful stakeholder engagement can overlook factors considered relevant and influential by stakeholders. This paper presents an inter-discursive approach to grounding conventional mixed methods evidence synthesis in stakeholder views of adolescent perinatal health in Canada. Methods A parallelresults convergent mixed review identified studies reporting on perinatal outcomes and experiences of adolescents during pregnancy to 12 months post-partum, in French or English, published in Canada after 2000. We summarized findings using thematic synthesis and descriptive statistics. We then extracted data from a provincial database of maternal and newborn outcomes and calculated relative risks for common perinatal risk factors and outcomes for adolescents compared to adult population within a local health region and across Ontario from 2012-2017. Two trained peer researchers contributed to our evidence syntheses. We shared syntheses with four service providers and 13 marginalized adolescent mothers, who identified and prioritized their areas of concern. A second literature review refocused around the priority issues identified by the women and was then expanded through semi-structured interviews. Results Adolescent mothers face more poverty, higher rates of abuse, anxiety and depression than adult mothers. They also report experiencing negative judgments when accessing services, highlighting the need for more youth-friendly services. Adolescent women prioritized the experience of judgment in perinatal health and social services, and more specifically how they felt judgment contributed to them being identified as a child protection risk. Other priorities included inadequate housing, judgment around breastfeeding, loss of social support and inaccessibility of community resources. Judgment in the adolescent perinatal health literature was summarized around three themes: being invisible, incapable and at risk. Adolescent mothers adapted and added onto these categories, emphasizing organizational and social challenges, with important consequences for their mental health and accessing appropriate care. Conclusions Incorporating young women's voices changed the focus of our research. Women's priorities highlighted the way motherhood norms are embedded in social and institutional structures. Adolescent women's experiences of care have important implications for ensuring the effectiveness of more targeted interventions to maximize benefit to women and newborns.

\section{Background}

Despite Canada's investment in universal and accessible health services, stubborn health inequities continue and follow predictable social fault lines: people living in worse socioeconomic conditions have poorer health than those with greater access to resources and educational opportunities. (1-3) By international standards, Canada has a low maternal mortality rate (6.1/100 000 births). (4) Women living in lower socio-economic conditions, however, often face greater levels of chronic stress related to poverty, lack of social support, and violence. $(5,6)$ Several studies show women living in low socio-economic conditions have worse perinatal outcomes and lower use of prenatal and postpartum care. $(1,6-10)$

Marginalized women are disproportionately affected by inequities in perinatal outcomes, yet their perspectives are rarely featured in efforts to address these inequities. (11) A disjointed Canadian surveillance system is unable to capture maternal health indicators among some of the country's most vulnerable citizens. (12) Those at the margins are rarely heard in institutional decision-making and, therefore, they have little influence over research and clinical practice. (11)

Adolescent women are among the populations in Canada that experience higher risk factors and poorer outcomes. Increased risks associated with adolescent pregnancies include preterm and very preterm delivery, low birth weight, small for gestational age infants, and neonatal and infant mortality. (13-15) Although socioeconomic and behavioural factors like smoking, alcohol and drug use, poor nutrition, and poor prenatal care are also risk factors, 
young maternal age remains an independent risk factor for these outcomes after adjusting for potential confounders. (15) Significant resources are dedicated to reducing unplanned pregnancies in adolescence. The fertility rate among adolescents aged 15-19 has declined from 11.9 in 2012 to 8.4 in 2016. (16) This is primarily due to improved sexual education and increased access to contraception and abortion. (13)

We used modern participatory methods to ground available evidence in the lived experience of adolescent mothers to identify and better understand priority issues affecting their care as pregnant and parenting adolescents. As part of a larger initiative, this paper describes two meetings with young mothers, the first to determine the focus of the research project, and the second as an exploration of the chosen focus issue.

\section{Methods}

With the help of a health sciences librarian, we searched Medline, CINAHL and Web of Science for primary research describing perinatal (during pregnancy to 12 months post-partum) health outcomes and experiences of adolescent women (under 23 years of age) in Canada, including all articles published in French or English after the year 2000. The primary author screened all abstracts, read and extracted data from all eligible articles. We assessed the quality of qualitative studies using the Critical Appraisal Checklist for Qualitative Research. (17) We extracted findings as a standard parallel-results convergent synthesis mixed method review, using inductive thematic synthesis with NVivo to analyze qualitative data and descriptive statistics for quantitative data. (18-20)

We also analyzed data from the Better Outcomes Registry Network (BORN), a database on pregnancy, birth and childhood outcomes for the province of Ontario. We extracted data on common perinatal health indicators (such as pregnancy rates among adolescents, preterm births, access to antenatal care, labour and birth complications) as well as specific indicators commonly reported among adolescent pregnancies (substance use, sexually transmitted infections, mental health concerns, experience of abuse). We calculated relative risks for adolescents for each indicator by year and over the 5-year period for both the province and the relevant local health integration network from 2012-2017.

\section{Engaging Peer-researchers}

Ottawa-based staff from a social service organization for young pregnant and parenting women helped to identify two peer researchers with lived experience as young mothers. AK joined the project, along with another co-researcher, after 10 hours of peer researcher training, adapted and delivered by the primary author (AD). $(21,22)$ Both peerresearchers were paid during their training and when contributing to the project.

\section{Determining Priorities}

The primary author and peer-researchers reviewed statistics of outcomes and risk factors from quantitative studies along with themes, quotes and images from qualitative studies. We discussed which findings might be most relevant to young mothers accessing services at our partner agency. AD summarized selected findings in an infographic, which was further refined by both peer researchers. The infographic was shared with four service providers from the fields of obstetrics, mental health, nursing and social work, all involved in providing front line services to pregnant and parenting young people in Ottawa. They individually identified what they felt were priority challenges in the perinatal health and well-being of their clients, and then grouped common themes between them. Each provider was given five stickers to allocate to the challenge they felt was most important to young mothers' well-being, specifying that they 
could place more than one sticker per issue. Priority issues were summarized and included in the next step of sharing information with young mothers.

Using information postcards, short presentations and support from our partner agency, we invited young women to join an information and priority setting meeting at our partner agency. Following brief introductions and an informed consent process (detailed below), we shared and reviewed the evidence synthesized in the infographic and invited participants to tour a collection of nine pictures and quotes from published qualitative studies, selected by the peer researchers. We emphasized that this information represented how young motherhood was discussed in research literature, and that some aspects may be relevant to their own experiences, while others may not.

We asked each participant to identify areas or issues that were important to them where they faced challenges or barriers throughout their pregnancy and early postpartum experience. We prompted participants to draw from the literature, priority issues identified by service providers, as well as their own experiences. Participants wrote their ideas on post-it notes. Where comfortable, participants presented their issue, briefly describing why it was important and placed it on the wall. As each subsequent participant shared their issue, they determined whether their issue could be grouped with one already posted on the wall or if it addressed a separate issue. (21) Any participants who did not want to present their issue themselves could hand their post-it notes to the two facilitators (AD and AK) as we circulated around the room. Before moving on to the next step, we asked participants to adjust any grouping or descriptions of their own topics if they felt their idea had changed or was miscategorised. We also included priority themes identified by service providers if they were not already mentioned for women to include in their evaluation.

Each participant received five voting stickers to identify the most important challenges faced by young mothers, and they could place more than one sticker per issue. We then drew on sticker voting to re-organize issues according to importance. We gave participants an additional two stickers each, asking them to identify among those identified in the first round, their first (red) and second (yellow) priority concern.

We finalized the priority issues through group discussion, and participants were asked to write the answers to the following two questions with respect to the issue identified as the top priority: Why is this important? What do we still need to know about this? (22)

\section{Grounding Evidence}

Following the priority-setting meeting, we returned to our literature review to extract findings related to the priority issue. We compared themes identified in each of the papers together with the quantitative data to identify secondorder themes around the priority issue. Second-order themes are grounded in evidence from the original studies but are the result of an interpretation across the collection of studies. (23) AD identified primary and second-order themes related to the priority issue, which were subsequently adapted by the peer researchers. We used these themes to guide an additional round of conversations with women. We carried out individual or small group meetings with 10 young mothers, where we asked participants to describe their own experiences related to the priority issue throughout pregnancy and early postpartum. We worked with participants to distil their main ideas and wrote them on small magnets.

We then presented the second-order themes identified in the literature on a magnetic whiteboard, emphasizing that these were concepts identified from the literature, but may not capture all their experiences. We asked participants to map out (using a small whiteboard) how their own ideas fit within (or not) the concepts identified in the literature. We also presented the primary themes identified from the individual papers and invited participants to incorporate into 
their map where relevant. The lead author and peer researcher independently reviewed the conceptual maps and notes from each of the interviews and developed a list of common themes. These themes were compared and refined to reach a final set of themes identified by participating women.

\section{Participatory inter-discursive evidence synthesis}

We piloted all elements of the approach with peer researchers and adopted strategies to support meaningful engagement with young mothers including efforts to be youth friendly and build trust, and taking a scaffolded and iterative approach that included multiple opportunities for consent.

Youth-friendly and accessible information: We adapted our consent forms to ensure that language was understandable and accessible to potential participants. Together with peer-researchers, we prepared a general information sheet about the study and separate one-page consent checklists for each meeting in short question and answer formats. (24) This allowed people to understand the direction of the overall project, while deciding whether to participate in the one meeting without committing to the whole project. We opened each meeting with a discussion young people's rights when participation in research. Using a Charter of Rights for Children and Young People developed by Moore et al., we reviewed issues relating to participants' rights to be heard, to participate in the way they prefer, to be treated well and not be hurt or discriminated against, as well as to be fully informed and to benefit from the research. (25) Counseling staff from our partner organization was also available if anyone needed additional support.

Consent focussed: We relied on young women, all of whom were 16 years of age and older, to decide how and when to participate. Many clients of our partner organization have complicated or non-existent relationships with their parents or guardians, are already making important decisions for their children and engaging with many organizations as adults. While this often adds to their vulnerability as young parents, we felt it would be inappropriate and potentially harmful to ask potential research participants to seek parental consent to participate in this research project. (24) Given enough time and information, adolescents over the age of 15 years have the cognitive capacity to make informed decisions. (26)

Renegotiating consent: We incorporated multiple opportunities for participants to renegotiate consent, dissent or disengage at pivotal moments throughout this research. This included periodically checking in with participants to ensure they were comfortable continuing and encouraging people to step outside the room if they needed to. (27) Some women described experiences or events but were uncomfortable with representing them on the whiteboards. Facilitators supported the distilling of ideas, but women decided how their experiences were described, represented or even included on the whiteboard, emphasizing that they also had the right to have parts of their story not told. (28)

Scaffolded and iterative: Each activity built on a previous discussion. In a first meeting, young women decided what issues were most relevant to them. Subsequent discussions focused on issues identified by young women, bringing in relevant findings from research to inform the discussions. Each discussion served as an opportunity to ground research findings in the experience of young women. $(27,29)$ Our approach sought to provide young women the same level of research evidence as other decision-makers, giving them the information that might be necessary to make evidence informed decisions around their care.

Compensation: We worked with our partner organization and peer-researchers to determine appropriate honoraria for participants. We provided child care, bus passes and snacks during each meeting to ensure that participants could engage comfortably in discussions. We also provided $\$ 30$ gift cards for each 2-hour meeting in recognition of their 
knowledge and expertise. We chose to distribute these at the beginning of each meeting (after the consent process) as a sign of trust and so that participants did not feel obliged to stay if they were uncomfortable throughout the meeting. (30)

Building Trust: AD served as a volunteer birth companion in Ottawa for nine years, informing the overall research approach. Prior to engaging with young women as participants in this research project, AD was a respite volunteer for young mothers at our partner organization's shelter once a week for over a year before and throughout the project. Many women knew AK as a fellow client of our partner organization. This helped to build trust with participants and create familiarity with our partner organization's activities.

\section{Results}

\section{Literature Review}

Our search identified 771 publications. The lead author (AD) assessed all abstracts to determine eligibility and extracted data from 28 relevant articles (13 quantitative, 15 qualitative). All studies included women under the age of 23 who had a singleton pregnancy. Tables $1 \mathrm{~A}$ and $2 \mathrm{~A}$ show summary data from studies reporting risk factors and outcomes comparing adolescents with adult populations respectively, while Tables $1 \mathrm{~B}$ and 2B show summary data from studies with adolescents accessing community and outreach services for marginalized and pregnant youth. Heterogeneity across studies precluded pooling of quantitative data. Full data tables can be found in Additional File 1.

Pregnant adolescents were $10-47 \%$ less likely to attend prenatal care in the first trimester, often citing financial barriers, long waiting times, lack of privacy, fear of judgment and not wanting to miss school. (13) Adolescent mothers were also more likely to have concurrent mental health issues and additional social and economic risk factors that may affect their pregnancy. Most young mothers were single $(\mathrm{OR}=2.66(1.69-4.18))$ and were more likely to have a low income (less than $\$ 40 \mathrm{~K}$ a year). (31) Adolescent mothers were twice as likely to be at risk for postpartum depression compared to adult mothers. (32) Roughly $60 \%$ of young mothers accessing care at a youth pregnancy outreach clinic either completed or were in the process of completing high school. $(33,34)$ Youth in foster care were four times more likely to become pregnant compared to other teens. (35)

Table 3 shows relative risks from the BORN database, comparing risks and outcomes in adolescent (under 23 years) and adult pregnancies in the Champlain Local Health Integration Network and across Ontario. Ontario adolescents were more likely than adults to have a mental health diagnosis of anxiety, depression as well as other mental health disorders, consistent with higher age-specific fertility rates among adolescents with major mental illness reported in the literature. (36) Pregnant and/or parenting adolescents were 2-4 times more likely to have ever experienced physical abuse $(14,31)$ were more likely to have used drugs $(R R=5.63(5.41-5.84))$ or alcohol $(R R=2.33(2.22-2.44)$ during pregnancy and were more likely to be diagnosed with a sexually transmitted infection during pregnancy $(R R=$ $2.77,2.62-2.93)$. Adolescent mothers were roughly one half as likely to have a Caesarean section or breastfeed compared with adult women and were $16 \%$ more likely to deliver preterm. $(13,15)$

Themes identified in qualitative studies (Table 4) reflect the complexity of emotions surrounding pregnancy and motherhood. Women express deep gratitude for their experience of pregnancy and their children, while also feeling that an unfair burden of responsibility and social stigma surrounds their mothering experience. (37) They describe challenges in navigating education, employment, social services for themselves and their children while facing negative judgment. $(37,38)$ 


\section{Determining Priorities}

Peer researchers highlighted outcomes, themes and quotes they found relevant to the experiences of the women accessing services at our partner organization. After multiple rounds of feedback, we developed the evidence infographic in Figure 1. Peer researchers also chose nine quotes and photographs from the four qualitative studies that used PhotoVoice methodologies to include in the priority setting meeting. $(38,39,41,42)$

Table 5 presents priority concerns as identified by service providers, and by the women who participated in our priority setting meeting. Service providers identified concerns around mental health- both recognizing the need for and accessing services- as an important challenge for pregnant and parenting youth. They also discussed the influence of stigma and fear of the consequences of being vulnerable as a critical factor influencing perinatal well-being, highlighting the need for trauma-informed and culturally-informed programming. They saw young women's on-going precarity due to poverty, housing instability and the need for independent living skills as factors contributing to young women's overall vulnerability.

Thirteen women aged 17-25 participated in our priority-setting meeting. Participants' children ranged in age from one month to 4 years old, with women having between 1 and 4 children each, and varying levels of custody over their children. Women (almost universally) identified the experience of being judged or misunderstood as the most important challenge throughout their maternity and early motherhood experiences. Women experienced judgment in everyday experiences, such as riding the bus or grocery shopping, which was a source frustration that eroded their sense of confidence. Judgment was particularly challenging with respect to breastfeeding, as many reported having comments made to them or were asked to not breastfeed their infants in public.

"Young moms and moms in general are still constantly being shamed and ridiculed for breastfeeding in public. If a baby is hungry, feed the little one...... it makes me mad when I see women being shamed for it. If you don't like to see it, look the other way."

After discussing women's experiences of judgment across multiple areas of their lives, we invited women to vote a second time, identifying their most important concerns with respect to judgment. Women identified the experience of judgment as it relates to being identified as a child protection risk as well as how judgment affects access to secure housing for themselves and their children. Several women mentioned that many of their interactions with child protection workers themselves have been positive, but women collectively explained that initial reports to the Children's Aid Society's were uninformed or made without adequate investigation. Women sought to be seen for their strengths as well as challenges, despite and not because of their age, and emphasized early and non-judgmental support to prevent the need for child protection involvement. This priority area was further explored with participants in subsequent meetings and described in forthcoming publications.

\section{Unpacking judgment and its consequences}

Following this priority setting meeting, we returned to the published literature to identify themes related to the experience of judgment and its consequences. We then met with 10 women in follow-up meetings either individually or in pairs, and worked with women to distil ideas, issues or themes from their own experiences of judgment throughout pregnancy and early motherhood. Table 6 shows the demographic characteristics of the women participating in these meetings. Several women reported using illicit drugs; cannabis was illegal at the time of these interviews, and therefore also included in this category. 
Second-order themes identified in the literature included being regarded as a risk, invisible and incapable, shown in Table 7. Women arranged their ideas around these three second-order themes or created new ones when they felt other categories were needed. They subsequently incorporated the primary themes describing experiences judgment from the literature (Table 6) that they felt were relevant to their own experience.

Finally, we asked participants to describe the consequences or effects of each type of judgment listed and distilled these onto small magnets to be included on their map. We presented consequences of judgment identified from the literature and again, asked participants to incorporate themes relevant to their own experience.

Women described feeling discounted or quickly judged by service providers who didn't understand the broader context of women's lives and experiences around their pregnancy and/or postpartum concerns. Women were frustrated by experiences of surveillance and judgment rather than support when they disclosed needs around housing, low income, or other health and social concerns.

"They judge you for something you didn't even know you are doing. They make you feel like you are not capable of being a good mom....instead they should try to help you become the best mom you can be."

Several women also discussed the paradox of being a young mother, where they experienced administrative barriers in navigating health and social service systems. They were expected to manage the responsibilities of new motherhood as an adult, while simultaneously being a child and "not being taken seriously". In the words of one participant "I am old enough to have a baby.....but not old enough to consent?!?", describing the contradiction in being able to consent for medications for her infant, but not being recognized as an adult capable of consenting for her own medical needs.

Women linked experiences of negative judgment with their mental health concerns, including higher levels of stress, frustration and in some cases anger. They reported feeling as though they always second-guessed themselves, and that they were made to feel incompetent before being given a chance.

"When I had my first child in the hospital, people just took over, figured I had no idea what I was doing. They just took it upon themselves to take over with the assumption that I wasn't going to do it myself."

"I sneeze and it is judged; I go to the bathroom and I wonder if it is okay.....you cannot function as a human if you are always in doubt"

These experiences contributed to women feeling as if they had no voice in or control over their care, undermining their position as primary caregivers. Some women reported feeling that their consent in the care and handling of their child was not respected and reacted by becoming hyper-vigilant and protective in interactions with health and social service providers. One woman reported limiting her sleep in the hospital both ante and post-partum for fear that decisions about her newborn's care would be made without her.

Several women reported avoiding services or not fully disclosing needs for fear of judgment or being seen as incapable or a risk. This left them with unmet needs, particularly around mental health.

"I also had to balance not saying too much. I couldn't say what I really feel- like admitting feeling suicidal would be seen as a risk to my child, and would be reason to justify her removal or the removal of my rights."

"Even postpartum, it felt that it took excessively long to get a referral to perinatal mental health. I received great care for anything that directly affected baby's health, but my mental health didn't fall into that." 
Women reported feeling let down or judged by those they thought could support them; in many cases, losing social support from friends, partners and sometimes family, upon learning they were pregnant. Women often spoke about isolation and harassment from friends at school or work, unsupportive teachers and/or family members who may disapprove of their pregnancy and/or their partners.

"It is judgment from the people that have meant something to me that hurts the most"

Women felt they did not have enough information about programs and services available to them, particularly those focused on the needs of pregnant and/or parenting adolescents. This left many women with a heavy burden of responsibility, while isolated from their previous support network.

Several women described unhealthy or dangerous family situations, stating that for them, isolation from these relationships was often difficult but necessary. Some women reported having to push back against conventional perceptions of sources of social support.

"Then she began to be really opinionated about me needing to get back together with my son's dad. Eventually, I told her that I didn't want to go back to being beaten every day and she backed off........Isolation is seen as a bad thing, but when your support network isn't good for you, sometimes it is the best thing."

Women also described feeling permanently labeled based on their needs or events in their lives, over which they had little control. Examples included having had child protection involvement in their own childhood or by what were seen as choices to remain in abusive or violent relationships.

"They see you only for your risks.... when people look at me, nobody sees my future plans, just my present problems."' "We don't need to be hovered over-we aren't terrible or scary people, or that we have no idea what we are doing. Some of us are in bad situations or made some poor choices along the way, but it doesn't mean we don't know anything or how to do anything"

"I have a mild form of autism, so that brought additional judgment. They were telling me that I shouldn't be having kids because....neither of us will know what to do with it."

As a counter to these experiences, women highlighted how they resisted judgment and its consequences. For many women, this meant recognizing their own strengths and affirming their identity as mothers. Many women reported seeking out additional learning resources to support their decision-making around pregnancy and early parenting. Women invested considerable mental and emotional energy in controlling the narrative in how they were perceived, learning to advocate for themselves and their children early on:

"You can either deal with judgment and live your life, or hide away. I hid for a while but then I decided I just didn't care what other people think, but I had to grow up fast to get there."

"I feel I often have to fight to make myself heard over my pediatrician; I have to not back down. I had to go through multiple prescriptions for [my son's condition] because she assumed that I was doing it wrong. She didn't see that I understood, but that the medication just wasn't working."

Women also reported refusing support that did not meet their needs. Women's refusal often resulted in being labelled as non-compliant or seen as a potential risk. 
"I wasn't interested in participating in an arts and crafts program but had to, as well as other programming that I didn't find helpful. I pushed back against the rules because I didn't feel they were helpful or what I needed."

"I am generally uncomfortable with males (particularly male authority figures) and didn't want a man examining my baby, so when the male resident came to examine my daughter, I refused the exam."

Women also emphasized the importance of supportive relationships as a counter to experiences of judgment that helped them benefit from health and social services and prevent difficult circumstances from evolving into more serious risks for themselves and their children. This often included family members and close friends, however, also included health and social service professionals, including ward and public health nurses, lactation consultants, physicians, early childhood educators and child protection workers. Many women highlighted adolescent-specific services as being particularly supportive, however they also cited several examples in mainstream services.

"What made a big difference for me was having someone speak to me - for me it was my mum and grandmother telling me that I am a good person, that I can do this. They made me believe in myself."

"There were some good people at the hospital- they showed that they had faith in me and took the time to spend some time with me, and believed in my skills. One of these was a lactation consultant, who stood up for me within the hospital and with other professionals."

\section{Discussion}

Incorporating adolescent women's voices changed the focus of our research. While issues of negative judgment appear in qualitative literature on adolescent pregnancy, how young people experience this and its consequences are rarely explored. Our focus was to ensure meaningful participation of young people and our approach was driven by their experiences and concerns during pregnancy and early motherhood.

Rigidly gendered social norms around motherhood continue to play a large role in the experience of adolescent motherhood. (43-46) People who deviate from prevailing norms around motherhood are often seen as risky or unfit. In many cases, their perceived riskiness is seen as an individualized choice, with insufficient consideration of the context and structural influences. (37) Women described barriers to participation they found built into the architecture and organization of institutions. This affected their access to health, including being recognized as their child's guardian and parent, opportunities for education, financial support, housing and in navigating child protection issues. These systemic barriers exacerbate existing vulnerabilities, even in the absence of individual prejudice or discrimination on the part of care providers. (47)

Repeatedly being labelled often becomes internalized, and can influence people's willingness to seek care, as well as how care is delivered, received, what is shared, what is acted upon and what is refused. $(28,47-50)$ Expecting and fearing rejection, women guarded or avoided potentially threatening interactions all together. All the women in our study mentioned the mental health consequences of repeatedly feeling judged, having their identity as mothers be undermined or questioned and the emotional work required to try to manage how they were perceived.

Women who are seen as outside of the conventional norms around motherhood also experience more frequent controls or access restrictions through both formal and informal interventions. (51) In our work, women described how they felt that judgment or a mischaracterization of their situation often led to restrictions on their activities and over-surveillance of their pregnancy and mothering. 
The findings of this study have several implications for research and the provision of perinatal care for young people. Many women saw judgment and stigma associated with their positions as mothers as something they just have to live with. At a practical level, this is probably true. However, researches, clinicians and care providers are in a position to change the extent to which judgement shapes all maternity and early parenthood experiences, and especially among those who may face high levels of stigma by changing their own practices as well as advocating for broader systems level changes.

One way of doing so is by centering the experience of people living with the everyday effects of being made vulnerable. They are the most relevant voices to speak about how this vulnerability intersects with perinatal care, and ultimately influences their own and their family's health and well-being. Services designed solely by those who identify with more privileged groups are unlikely to address the additional or different needs of less privileged groups, often leaving already marginalized groups underserved and further excluded. (52) Despite personal intentions to provide the best care possible, perinatal care providers may find themselves with limited ability to meet the needs of marginalized groups. $(53,54)$ When policies and resource allocations do not match community needs, providers may lack the support of strong inter-professional collaborations, with patient follow-up falling through cracks between different organizations or care teams.(55-57) This can leave providers frustrated and feeling powerless while also leaving women feeling isolated and without adequate support. Women may find themselves labeled as "noncompliant" when they cannot access care in a system that does not adequately consider their needs. $(52,58,59)$

In a matched cohort study, Fleming et al. found that adolescents receiving specialized multidisciplinary communitybased perinatal care had higher rates of prenatal visits, prenatal class attendance and group B streptococcus screening compared to adolescents across the province on Ontario. Although women accessing community-based perinatal care had higher levels of tobacco, alcohol and other substance use than the control group, those accessing community-based care had significantly lower risks of low birth weight and preterm delivery. (53)

The dynamic and multi-layered nature of young people's perinatal care needs requires a broad consideration of outcomes. While focused programs and interventions need continued support, interventions are also needed to shift deeply held attitudes and beliefs that lead to labelling, devaluing and discriminating. Alternatively, interventions must contribute to limiting the processes that make these perceptions the dominant ones. $(47,50,60)$ While these are broader societal issues, ensuring the optimal health of families needs to be carried out in a context where compassion, understanding, encouragement and respect for parents are the foundational and enacted values.

Research also has an important role to play in shifting our understanding towards more people-centered health systems and services. Recognizing the value of lived experience can strengthen our understanding of the influence of social and organizational contexts in health interventions. (61) Considering people's experience as expertise recognizes that there is more than one piece to a puzzle and that putting the knowledge and experience of people who are living with vulnerabilities on equal footing with other types of knowledge is critical to challenging assumptions often implicit in clinical research and the provision of services. $(62,63)$ This is particularly important in communities that are stigmatized, where incorrect assumptions or representations may reinforce negative or incorrect stereotypes.

\section{Conclusions}

Young mothers have priorities in their perinatal care that might not be well understood without detailed consultation. An iterative process grounded conventional evidence syntheses in young women's experiences, deepening our understanding of the role of judgment in shaping perinatal care. Women explained how their experiences of judgment

Page $11 / 22$ 
around pregnancy and parenthood had important implications for their mental health, identity as mothers, and access to services. They emphasized the importance of supportive relationships and their role as advocates to counter experiences of judgment.

Service delivery and evaluation should take better account of service users' understanding of how determinants of health intersect with conventional biomedical evidence. This is particularly urgent in the context of health inequities, where perspectives of those who carry the greatest burden of inequities are often poorly reflected in published literature.

\section{Declarations}

\section{Ethics Approval}

Ethics approval was received from the McGill Faculty of Medicine Ethics Review Board (A09-B51-17A). An Advisory Board made of senior staff of our partner organization also refined and approved this research.

Informed consent was obtained from all participants prior to data collection.

\section{Consent for Publication}

Not applicable

\section{Availability of Data and Materials}

Not applicable

\section{Competing Interests}

The authors declare that they have no competing interests.

\section{Funding}

AD holds a doctoral scholarship from the Pierre Elliott Trudeau Foundation.

\section{Authors' Contributions}

$A D, A N$ and NA conceived of the study, $A D$ and $A K$ carried out the research, $A D, A K$ and NA carried out the analysis. $A D$ drafted the manuscript and $A K, A N$ and NA made substantive revisions.

\section{Acknowledgments}


This work was carried out on the traditional and unceded territories of the Algonquin nation. We are grateful to all those who shared their experiences with us. We are also grateful to St. Mary's Home in Ottawa for their support and collaboration in this research.

\section{References}

1.Kramer M, Segiun L, Lydon J, Goulet L. Socio-economic disparities in pregnancy outcome: why do the poor fare so poorly? Paediatr Perinat Epidemiol. 2000 Jun 28;14:194-210.

2.Joseph KS, Huang L, Dzakpasu S, McCourt C. Regional disparities in infant mortality in Canada: a reversal of egalitarian trends. BMC Public Health. 2009;9(1):4-9.

3.Victora CG, Requejo J, Barros A, Berman P, Bhutta ZA, Boerma T, et al. Countdown to 2015: a decade of tracking progress for maternal, newborn, and child survival. The Lancet. 2016 May 14;387(10032):2049-59.

4.Canadian Institute for Health Information. Highlights of 2011-2012 Selected Indicators Describing the Birthing Process in Canada. 2013 Jun pp. 1-8.

5.Mikkonen J, Raphael D. Social Determinants of Health: The Canadian Facts. York University School of Health Policy and Management; 2010 May pp. 1-63.

6.Daoud N, OCampo P, Minh A, Urquia M, Dzakpasu S, Heaman M, et al. Patterns of social inequalities across pregnancy and birth outcomes: a comparison of individual and neighborhood socioeconomic measures. BMC Pregnancy and Childbirth. 2014 Mar 16;14:393.

7.Chalmers B, Kaczorowski J, Levitt C, Dzakpasu S, OBrien B, Lee L, et al. Use of Routine Interventions in Vaginal Labor and Birth: Findings from the Maternity Experiences Survey. Birth. 2009 Feb 26;36:13.

8.Joseph KS, Liston RM, Dodds L, Dahlgren L, Allen AC. Socioeconomic status and perinatal outcomes in a setting with universal access to essential health care services. Canadian Medical Association Journal. 2007 Sep 11;177(6):583-90.

9.Auger N, Giraud J, Daniel M. The joint influence of area income, income inequality, and immigrant density on adverse birth outcomes: a population-based study. BMC Public Health. 2009;9(1):237-11.

10.Landy CK, Sword W, Ciliska D. Urban women's socioeconomic status, health service needs and utilization in the four weeks after postpartum hospital discharge: findings of a Canadian cross-sectional survey. BMC Health Services Research. BioMed Central; 2008 Oct 3;8(1):203.

11.Serrant-Green L. The sound of "silence": a framework for researching sensitive issues or marginalised perspectives in health. Journal of Research in Nursing. 2011 Jul 5;16(4):347-60.

12.Allen V, Campbell M, Carson G, Fraser W, Liston R, Walker M, et al. Maternal Mortality and Severe Maternal Morbidity Surveillance in Canada. Journal of Obstetrics and Gynecology of Canada. 2010 Dec 1;32(12):1140-6.

13.Fleming N, Ng N, Osborne C, Biederman S, Yasseen AS3, Dy J, et al. Adolescent pregnancy outcomes in the province of Ontario: a cohort study. J Obstet Gynaecol Can. Canada; 2013;35(3):234-45. 
14.Kingston D, Heaman M, Fell D, Chalmers B, on behalf of the Maternity Experiences Study Group of the Canadian Perinatal Surveillance System, Public Health Agency of Canada. Comparison of Adolescent, Young Adult, and Adult Women's Maternity Experiences and Practices. PEDIATRICS. American Academy of Pediatrics; 2012 May 1;129(5):e1228-37.

15.Shrim A, Ates S, Mallozzi A, Brown R, Ponette V, Levin I, et al. Is Young Maternal Age Really a Risk Factor for Adverse Pregnancy Outcome in a Canadian Tertiary Referral Hospital? J Pediatr Adolesc Gynecol. 2011 Aug; $\{24\}(\{4\})$ : $\{218-222\}$.

16.Provencher C, Milan A, Hallman S, DAoust C. Report on the Demographic Situation in Canada. Government of Canada; 2018 Jun.

17.Joanna Briggs Institute. Critical Appraisal Checklist of Qualitative Research [Internet]. Joanna Briggs Institute; 2017 Apr. Available from: https://joannabriggs.org/sites/default/files/2019-05/JBI_Critical_Appraisal-

Checklist_for_Qualitative_Research2017_0.pdf. Accessed June 2017.

18.Pluye P, Hong QN. Combining the Power of Stories and the Power of Numbers: Mixed Methods Research and Mixed Methods Reviews. Annu Rev Public Health. 2014 May 5;35:29-45.

19.Popay J, Roberts H, Sowden A, Petticrew M, Arai L, Rodgers M, et al. Guidance on the Conduct of Narrative Synthesis in Systematic Reviews. 1st ed. 2001 Apr.

20.Braun V, Clarke V. Using thematic analysis in psychology. Qualitative Research in Psychology. 2006 Mar 2;3(2):77101.

21.Chevalier J, Buckles D. Handbook for Participatory Action Research, Planning and Evaluation. Ottawa: SAS2 Dialogue; 2013. 155 p.

22.Access Alliance Multicultural Health and Community Services. Community-Based Research Toolkit: Resource for Doing Research with Community for Social Change. Access Alliance Multicultural Health and Community Services; 2011 Jun.

23.Dixon-Woods M, Booth A, Sutton AJ. Synthesizing qualitative research: a review of published reports. Qualitative Research. 2nd ed. 2016 Aug 15;7(3):375-422.

24.Flicker S, Guta A. Ethical Approaches to Adolescent Participation in Sexual Health Research. J ADOLESC HEALTH. 2008 Jan;42(1):3-10.

25.Moore T, McArthur M, Noble-Carr D. More a marathon than a hurdle: towards children's informed consent in a study on safety. Qualitative Research. 2018 Jan 16;18(1):88-107.

26.Bruzzese J, Fisher CB. Assessing and enhancing the research consent capacity of children and youth. Applied Developmental Sciences. 2003 Sep 4;7(1):13-26.

27.Moore T, Saunders V, McArthur M. Championing Choice-Lessons Learned from Children and Young People About Research and Their Involvement. Child Ind Res. 2nd ed. Springer Netherlands; 2010 Sep 15;4(2):249-67.

28.Tuck E. Suspending Damage: A Letter to Communities. Harvard Educational Review. 2009 Oct 10;79(3):409. 
29.Moore T, McArthur M, Noble-Carr D. Little Voices and Big Ideas: Lessons Learned from Children about Research. International Journal of Qualitative Methods. 2008 Jun 30;7:1-15.

30.Moore T, Noble-Carr D, McArthur M. Changing things for the better: the use of children and young people's reference groups in social research. International Journal of Social Research Methodology. Routledge; 2015 Dec 28;:1-16.

31.Al-Sahab B, Heifetz M, Tamim H, Bohr Y, Connolly J. Prevalence and Characteristics of Teen Motherhood in Canada. MATERN CHILD HEALTH J. 2012 Jan;16(1):228-34.

32.Kingston D, Heaman M, Fell D, Chalmers B, Surveillance CP, Canada PHA. Comparison of Adolescent, Young Adult, and Adult Women's Maternity Experiences and Practices. PEDIATRICS. 2012 May; $\{129\}(\{5\}):\{E 1228-E 1237\}$.

33.Singh V, Murphy N, Thompson G, Hick K. 119. Adolescent Mothers and Their Children: Experience in a Canadian Urban Setting. J ADOLESC HEALTH. New York, New York: Elsevier Science; 56:S62-31p.

34.Thompson G, Madigan S, Wentzel K, Dineley B, Lorber S, Shouldice M. Demographic characteristics and needs of the Canadian urban adolescent mother and her child. PAEDIATRICS I\& CHILD HEALTH. 2015 Mar; $\{20\}(\{2\}):\{72-76\}$.

35.British Columbia Provincial Health Officer, British Columbia Child and Youth Officer. Kids, crime and care- Health and well-being of children in care. British Columbia; 2009 Mar.

36.Vigod SN, Dennis CL, Kurdyak PA, Cairney J, Guttmann A, Taylor VH. Fertility Rate Trends Among Adolescent Girls With Major Mental IIIness: A Population-Based Study. PEDIATRICS. 2014 Feb 28;133(3):e585-91.

37.Rutman D, Strega S, Callahan M, Dominelli C. 'Undeserving' mothers? Practitioners' experiences working with young mothers in/from care. CHILD FAM SOC WORK. Wiley-Blackwell; 2002 Aug 1;7(3):149-59.

38.Gill R, Black AM, Dumont TM, Fleming NM. Photovoice: A Strategy to Better Understand the Reproductive and Sexual Health Needs of Young Mothers. J Pediatr Adolesc Gynecol. Elsevier Inc; 2016 Oct 1;29(5):467-75.

39.Fortin R, Jackson SF, Maher J, Moravac C. I WAS HERE: young mothers who have experienced homelessness use Photovoice and participatory qualitative analysis to demonstrate strengths and assets. Glob Health Promot. 2015 Mar 11;22(1):8-20.

40.Kaur J. "Being Stuck": Understanding the health-related and everyday lived experiences of young mothers in Rexdale, Ontario through a social determinants framework. Polzer J, editor. University of Western Ontario- Electronic Thesis and Dissertation Repository; 2014. pp. 1-139.

41.Levy L, Weber S. Teenmom.ca: A Community Arts-Based New Media Empowerment Project for Teenage Mothers. Studies in Art Education. 2011 Mar 6;52(4):292-309.

42.Levy L, Weber S. "Yes I am a mother and I am still a teenager": Teen Moms Use Digital Photography to Share their Views. Girlhood Studies. 2011 Feb 8;3(2):1-11.

43.Held V. Birth and Death. Ethics. 1989 Jan 1;99(2):362-88.

44.Rothman BK. In Labor: Women and Power in the Birthplace. New York: W \& W North and Co; 1991.

45.Gore A. Queering Family. In: Gumbs AP, Martens C, Williams M, editors. Revolutionary Mothering. 2016. pp. $142-4$. 
46.Young IM. Punishment, Treatment, Empowerment: Three Approaches to Policy for Pregnant Addicts. Feminist Studies. 1994 Jun 13;20(1):32-57.

47.Link B, Phelan J. Conceptualizing Stigma. Annual Review Of Sociology. 2001 Apr 16;27:363-85.

48.van Ryn M, Fu S. Paved With Good Intentions: Do Public Health and Human Service Providers Contribute to Racial/Ethnic Disparities in Health? American Journal of Public Health. 2003 Jan 21;93(2):248-56.

49.Baxter NN. Equal for whom? Addressing disparities in the Canadian medical system must become a national priority. Canadian Medical Association Journal. 2007 Dec 4;177(12):1522-3.

50.Phelan JC, Lucas JW, Ridgeway CL, Taylor CJ. Stigma, status, and population health. Social Science \& Medicine. Elsevier Ltd; 2014 Feb 1;103(c):15-23.

51.Burton-Jeangros C. Surveillance of risks in everyday life: The agency of pregnant women and its limitations. Nature Publishing Group; 2011 Oct 5;9(4):419-36.

52.Crenshaw K. Mapping the Margins: Intersectionality, Identity Politics, and Violence against Women of Color. Stanford Law Review. 1991 Jul 5;43(6):1241-99.

53.Fleming N, Tu X, Black A. Improved Obstetrical Outcomes for Adolescents in a Community-Based Outreach Program:A Matched Cohort Study. Journal of Obstetrics and Gynecology of Canada. 2012 Nov 29;Dec:1134-41.

54.Ordean A, Kahan M. Comprehensive treatment program for pregnant substance users in a family medicine clinic. Canadian Family Physician. 2011 Oct 31;57(November):e430-5.

55.Benoit C, Stengel C, Phillips R, Zadoroznyj M, Berry S. Privatisation \& marketisation of post-birth care: the hidden costs for new mothers. International Journal for Equity in Health. International Journal for Equity in Health; 2012 Oct $15 ; 11: 61$.

56.Freedman LP, Kruk ME. Disrespect and abuse of women in childbirth: challenging the global quality and accountability agendas. The Lancet. Elsevier Ltd; 2014 Sep 20;384(9948):e42-4.

57.Spitzer D. In Visible Bodies: Minority Women, Nurses, Time, and the New Economy of Care. Medical Anthropology Quarterly [Internet]. Blackwell Publishing Ltd; 2004 Dec 1;18(4):490-508. Available from: http://doi.wiley.com/10.1525/maq.2004.18.4.490

58. Higginbottom GMA. 'I have to do what I believe': Sudanese women's beliefs and resistance to hegemonic practices at home and during experiences of maternity care in Canada. BMC Pregnancy and Childbirth [Internet]. BMC Pregnancy and Childbirth; 2013 Feb 25;13(1):51. Available from: BMC Pregnancy and Childbirth

59.0'Mahony J, Donnelly T. Immigrant and refugee women's post-partum depression help-seeking experiences and access to care: a review and analysis of the literature. Journal of Psychiatric and Mental Health Nursing. Wiley/Blackwell (10.1111); 2010 Sep 2;17(10):917-28.

60.Geronimus A. Teenage Childbearing and Personal Responsibility: An Alternative View. Political Science Quarterly. 1997 Oct 24;112(3):405-30.

61. Harris J, Croot L, Thompson J, Springett J. How stakeholder participation can contribute to systematic reviews of complex interventions. Journal of Epidemiology \& Community Health. BMJ Publishing Group Ltd; 2016 Jan 
$11 ; 70(2): 207-14$.

62.Macaulay AC. Moving the Frontiers Forward: Incorporating Community-Based Participatory Research Into PracticeBased Research Networks. The Annals of Family Medicine. 2006 Jan 1;4(1):4-7.

63.Dion A, Joseph L, Jimenez V, Gutierrez AC, Ben Ameur A, Robert E, et al. Grounding evidence in experience to support people-centered health services. International Journal of Public Health. Springer International Publishing; 2018 Dec $11 ;: 1-6$.

64.Tuck E. Theorizing Back. In: Anyon J, editor. Theory and Educational Research Toward Critical Social Explanation. 2008. pp. 111-33. An Approach to Participatory Policy Analysis.

\section{Tables}

Table 1A: Risk factors among adolescent compared to adult pregnancies in Canada

\begin{tabular}{|l|l|l|l|l|l|l|l|l|}
\hline Author & $\begin{array}{l}\text { Previous } \\
\text { Mental } \\
\text { Health } \\
\text { Diagnosis* }\end{array}$ & $\begin{array}{l}\text { Income } \\
\text { (less } \\
\text { than } \\
\$ 40 \mathrm{~K})\end{array}$ & $\begin{array}{l}\text { Experienced } \\
\text { physical } \\
\text { abuse }\end{array}$ & $\begin{array}{l}\text { History of } \\
\text { Substance } \\
\text { Use }\end{array}$ & $\begin{array}{l}\text { Any } \\
\text { smoking } \\
\text { during } \\
\text { pregnancy }\end{array}$ & $\begin{array}{l}\text { Alcohol } \\
\text { during } \\
\text { pregnancy }\end{array}$ & $\begin{array}{l}\text { Not having } \\
\text { age- } \\
\text { appropriate } \\
\text { education }\end{array}$ & Single \\
\hline $\begin{array}{l}\text { Al-Sahab, } \\
2015\end{array}$ & & $\begin{array}{l}\text { OR=6.66 } \\
(2.98- \\
14.90)\end{array}$ & $\begin{array}{l}\text { OR=2.24 } \\
(1.53-3.29)\end{array}$ & & $\begin{array}{l}\text { OR=1.12 } \\
(0.72-1.73)\end{array}$ & $\begin{array}{l}\text { OR=0.54 } \\
(0.27- \\
1.08)\end{array}$ & & $\begin{array}{l}\text { OR=2.66 } \\
(1.69- \\
4.18)\end{array}$ \\
\hline $\begin{array}{l}\text { Vigod, } \\
2014\end{array}$ & $\begin{array}{l}\text { ASFR=2.95 } \\
(2.84-3.07)\end{array}$ & $\begin{array}{l}\text { ASFR= } \\
3.04\end{array}$ & & & & & & \\
& $(2.95-$ \\
$3.15)$ & & & & & & & \\
\hline $\begin{array}{l}\text { Kingston, } \\
2014\end{array}$ & & & $\begin{array}{l}\text { aOR=4.87 } \\
(3.44-6.90)\end{array}$ & $\begin{array}{l}\text { aOR=3.7 } \\
(2.47- \\
5.56)\end{array}$ & $\begin{array}{l}\text { aOR=4.9 } \\
(3.37-7.12)\end{array}$ & & $\begin{array}{l}\text { OR=1.92 } \\
(1.27-2.89)\end{array}$ & $\begin{array}{l}\text { OR=17.75 } \\
(13.49- \\
23.35)\end{array}$ \\
\hline
\end{tabular}

* Previous diagnosis of anxiety or depression; $\mathrm{OR}=$ odds ratio; $\mathrm{aOR}=$ adjusted odds ratio

Table 1B: Risk factors among adolescents accessing community and outreach services for marginalized and pregnant youth in Canada

\begin{tabular}{|c|c|c|c|c|c|c|c|c|}
\hline & $\begin{array}{l}\text { Previous } \\
\text { Mental } \\
\text { Health } \\
\text { diagnosis }\end{array}$ & $\begin{array}{l}\text { Low } \\
\text { Income }\end{array}$ & $\begin{array}{l}\text { Experienced } \\
\text { physical } \\
\text { abuse }\end{array}$ & $\begin{array}{l}\text { Experienced } \\
\text { sexual } \\
\text { abuse }\end{array}$ & $\begin{array}{l}\text { Experienced } \\
\text { emotional } \\
\text { neglect/abuse }\end{array}$ & $\begin{array}{l}\text { History of } \\
\text { Substance } \\
\text { Use }\end{array}$ & $\begin{array}{l}\text { Not having } \\
\text { age- } \\
\text { appropriate } \\
\text { education }\end{array}$ & $\begin{array}{l}\text { Child } \\
\text { Protection } \\
\text { Involvement } \\
\text { in Own } \\
\text { Childhood }\end{array}$ \\
\hline $\begin{array}{l}\text { Singh, } \\
2015 \\
(\mathrm{n}=90) \\
\end{array}$ & $58 \%$ & & & & & $44 \%$ & $60 \%$ & $30 \%$ \\
\hline $\begin{array}{l}\text { Thompson, } \\
2015 \\
(n=116)\end{array}$ & & & $37.8 \%$ & $29.7 \%$ & $51.6 \%$ & & $57 \%$ & $47 \%$ \\
\hline $\begin{array}{l}\text { Harrison, } \\
2014 \\
(\mathrm{n}=36)\end{array}$ & $78 \%(n=28)$ & $\begin{array}{l}42 \% \\
(n=15)\end{array}$ & & & & $\begin{array}{l}81 \% \\
(n=29)\end{array}$ & & $69 \%(n=25)$ \\
\hline $\begin{array}{l}\text { Fleming, } \\
2012 \\
(\mathrm{n}=1037)\end{array}$ & $\begin{array}{l}7.8 \%\left(\text { int**) }^{* *}\right. \\
\text { vs. } 4.8 \% \\
\text { (con**) }\end{array}$ & & & & & $\begin{array}{l}19.6 \% \\
\text { (int) vs. } \\
10.5 \% \\
\text { (con) }\end{array}$ & & \\
\hline $\begin{array}{l}\text { Romano, } \\
2006 \\
(\mathrm{n}=252)\end{array}$ & $33.30 \%$ & $28.8 \%$ & $21.10 \%$ & $24.20 \%$ & $26.60 \%$ & & & \\
\hline
\end{tabular}


* Previous diagnosis of anxiety or depression; ** int= intervention groud, con=control group

Table 2A: Pregnancy outcomes among adolescents compared to adults in Canada

\begin{tabular}{|c|c|c|c|c|c|c|c|c|c|}
\hline Author & $\begin{array}{l}\text { Pre- } \\
\text { eclampsia }\end{array}$ & $\begin{array}{l}\text { Preterm } \\
\text { Delivery }\end{array}$ & IUGR & $\mathrm{C} / \mathrm{S}$ & $\begin{array}{l}\text { Prenatal } \\
\text { Visits in } \\
\text { First } \\
\text { Trimester } \\
\end{array}$ & $\begin{array}{l}\text { Exclusive } \\
\text { b/f @ } \\
\text { discharge }\end{array}$ & $\begin{array}{l}\text { EPDS } \\
\text { above } 13\end{array}$ & $\begin{array}{l}\text { Admitted } \\
\text { to NICU }\end{array}$ & $\begin{array}{l}\text { Fetal } \\
\text { Death }\end{array}$ \\
\hline $\begin{array}{l}\text { Fleming, } \\
2013\end{array}$ & $\begin{array}{l}\text { aRR0.91 } \\
(0.83- \\
1.00)\end{array}$ & $\begin{array}{l}\text { aRR1.16 } \\
(1.02- \\
1.31\end{array}$ & $\begin{array}{l}\mathrm{aRR}=1.00, \\
(0.96-1.04\end{array}$ & $\begin{array}{l}\text { aRR }=0.57 \\
(0.55- \\
0.59)\end{array}$ & $\begin{array}{l}\mathrm{aRR}=0.53 \\
(0.51-0.55)\end{array}$ & $\begin{array}{l}\mathrm{aRR}=0.73 \\
(0.71- \\
0.76))\end{array}$ & & $\begin{array}{l}\mathrm{aRR}=1.08 \\
(1.02- \\
1.14)\end{array}$ & $\begin{array}{l}\text { aRR=1.02 } \\
(0.88- \\
1.18)\end{array}$ \\
\hline $\begin{array}{l}\text { Kingston, } \\
2012\end{array}$ & & & & $\begin{array}{c}\mathrm{aOR}=0.64 \\
(0.46-0.9)\end{array}$ & & & $\begin{array}{l}\mathrm{aOR}=2.29 \\
(1.48- \\
3.54)\end{array}$ & & \\
\hline $\begin{array}{l}\text { Shrim, } \\
2011\end{array}$ & & $\begin{array}{l}\mathrm{OR}=2.3 \\
(1.6-3.2)\end{array}$ & $\begin{array}{l}\mathrm{OR}=2.4 \\
(1.6-3.5)\end{array}$ & $\begin{array}{l}\mathrm{OR}=0.3 \\
(0.2-0.5))\end{array}$ & & & & $\begin{array}{l}\mathrm{OR}=2.1 \\
(1.5-3)\end{array}$ & $\begin{array}{l}\mathrm{OR}=3.8 \\
(1.9-7.5)\end{array}$ \\
\hline
\end{tabular}

Table 2B: Pregnancy outcomes among adolescents accessing community and outreach services for marginalized and pregnant youth in Canada

\begin{tabular}{|c|c|c|c|c|c|c|c|c|c|}
\hline & $\begin{array}{l}\text { Pre- } \\
\text { eclampsia }\end{array}$ & $\begin{array}{l}\text { Preterm } \\
\text { Delivery }\end{array}$ & LBW & IUGR & $\mathrm{C} / \mathrm{S}$ & $\begin{array}{l}\text { Intention } \\
\text { to } \\
\text { Breastfeed }\end{array}$ & $\begin{array}{l}\text { Rate of } \\
\text { Exclusive } \\
\text { b/f @ } \\
\text { discharge }\end{array}$ & $\begin{array}{l}\text { Maternal } \\
\text { hospitalization } \\
\text { postpartum }\end{array}$ & $\begin{array}{l}\text { Child } \\
\text { Protection } \\
\text { Involvement } \\
\text { with the } \\
\text { child }\end{array}$ \\
\hline $\begin{array}{l}\text { Singh, } \\
2015 \\
(\mathrm{n}=90)\end{array}$ & & & & & & & & & $65 \%$ \\
\hline $\begin{array}{l}\text { Fleming, } \\
2012 \\
(\mathrm{n}=1037)\end{array}$ & $\begin{array}{l}2.9 \% \text { (int) } \\
\text { vs } 4 \% \\
\text { (con) }\end{array}$ & $\begin{array}{l}\mathrm{aRR}=0.47 \\
(0.22- \\
1.00)\end{array}$ & $\begin{array}{l}\text { aRR=0.41 } \\
(0.18- \\
0.95)\end{array}$ & $\begin{array}{l}11.2 \% \\
\text { (int) } \\
\text { vs 3\% } \\
\text { (con) }\end{array}$ & $\begin{array}{l}9.2 \% \\
\text { (int) } \\
\text { vs } \\
13.7 \% \\
\text { (con) } \\
\end{array}$ & $\begin{array}{l}82.8 \% \text { (int) } \\
83.1 \% \\
\text { (con) }\end{array}$ & $\begin{array}{l}40.7 \% \\
\text { (int) vs } \\
45.6 \% \\
\text { (con) }\end{array}$ & & \\
\hline $\begin{array}{l}\text { Thompson, } \\
2015 \\
(n=116)\end{array}$ & & & & & & & & $19 \%$ & \\
\hline
\end{tabular}

Table 3: Pregnancy risks and outcomes in adolescent and adult pregnancies in the Champlain Local Health Integration Network and across Ontario, 2012-2017. 


\begin{tabular}{|c|c|l||l|l|}
\hline \multirow{2}{*}{} & \multicolumn{3}{|c|}{$2012-2017$} \\
\cline { 2 - 5 } & \multicolumn{3}{|c|}{ Champlain LHIN } & \multicolumn{2}{|l|}{ Ontario } \\
\cline { 2 - 5 } & RR & $95 \%$ CI & RR & $95 \%$ CI \\
\hline Self-report drug and substance use in pregnancy & 6.34 & $5.63-7.15$ & 5.63 & $5.41-5.84$ \\
\hline Self-report alcohol exposure in pregnancy & 1.38 & $1.18-1.59$ & 2.33 & $2.22-2.44$ \\
\hline Reporting mental health anxiety* & 1.76 & $1.62-1.9$ & 1.77 & $1.72-1.81$ \\
\hline Reporting mental health depression* & 2.05 & $1.88-2.24$ & 2.16 & $2.11-2.22$ \\
\hline Reporting other mental health conditions* & 3.05 & $2.65-3.52$ & 2.88 & $2.75-3.00$ \\
& & & \\
\hline (bipolar disorder, schizophrenia, and others) & & & \\
\hline Disclose abuse during pregnancy & 3.18 & $2.75-3.68$ & 2.76 & $2.64-2.90$ \\
\hline Did not attend prenatal care in 1st trimester** & 1.11 & $1.10-1.12$ & 1.10 & $1.094-1.098$ \\
\hline $\begin{array}{c}\text { Sexually transmitted infection during pregnancy*** } \\
\text { (chlamydia, gonorrhea, syphilis, HSV, HIV, HPV) }\end{array}$ & 1.98 & $1.59-2.46$ & 2.77 & $2.62-2.92$ \\
\hline Preterm Delivery (<37wks) & 1.11 & $0.99-1.24$ & 1.07 & $1.03-1.10$ \\
\hline Labour and birth complications (Atypical or abnormal fetal surveillance) & 0.99 & $0.93-1.06$ & 1.00 & $0.982-1.024$ \\
\hline Obstetrical Complications (IUGR/SGA, preterm delivery, UTI) & 1.51 & $1.35-1.68$ & 1.44 & $1.39-1.49$ \\
\hline
\end{tabular}

*Concerns during this pregnancy including those pre-existing, diagnosed during pregnancy or active during pregnancy. Both diagnosed or self reported;

**Before 13 weeks gestation

$* * *$ Infection identified during pregnancy

Table 4: Themes Identified in Qualitative Literature

\begin{tabular}{|l|l|}
\hline Theme & Illustrative Quote \\
\hline Motherhood as & "I was pregnant, and realized the path that I was going to bring another human being into. This was \\
Transformative & $\begin{array}{l}\text { my choice - so there were two paths for me to go on. To continue going on this one and bring a child } \\
\text { in that, not being in control of my life. And I knew that I couldn't do that to a child. So, making the } \\
\text { choice to go the straight path and know what is coming." (39) }\end{array}$ \\
\hline Judgment & "My social worker questioned my ability to mother properly." (40) \\
\cline { 2 - 3 } & $\begin{array}{l}\text { "It bothers me what other people think. I am trying really hard not to think about what other people } \\
\text { think about my mothering. Do you know what I mean? ... Because everyone is telling us that we } \\
\text { can't." (39) }\end{array}$ \\
\hline Control & $\begin{array}{l}\text { "And actually I had a friend that took something for the birth and it showed [in a subsequent drug } \\
\text { test] that she did drugs, when she's not that kind of person. And, they instantly took that baby ... So, I } \\
\text { didn't take anything [during labour]. It was pretty crazy. I was scared." (40) }\end{array}$ \\
\hline $\begin{array}{l}\text { Need for } \\
\text { Comprehensive } \\
\text { Support }\end{array}$ & $\begin{array}{l}\text { "I am not ashamed of being a teen mother. However I do feel that if someone had guided me when I } \\
\text { was going through my eating disorder, addictions, and insecurities that my life could have been } \\
\text { different." (38) }\end{array}$ \\
\hline $\begin{array}{l}\text { Poverty and } \\
\text { Meeting Basic } \\
\text { Needs }\end{array}$ & $\begin{array}{l}\text { "Umm, just healthy foods. I find that they're really hard to access. That ties in really huge with } \\
\text { women's health right?" (38) }\end{array}$ \\
\cline { 2 - 3 } & $\begin{array}{l}\text { "if you don't have a safe place to call home, then you're not going to be able to get any other supports } \\
\text { for yourself in place including anything for your sexual health." (38) }\end{array}$ \\
\hline
\end{tabular}

Table 5: Priority Areas to Support the Well-being of Pregnant and Parenting Youth, Identified by Service Providers and Young Women 


\section{Priority Areas Identified by Service Providers}

Mental Health

- $\quad$ Access to mental health services - Anxiety and Depression

- Untreated or undiagnosed mental health needs

Judgment

- Fear of being vulnerable; fear of being flagged as a risk to Child Protection

Past Traumatic Experiences

- Impact of childhood trauma on parenting

- Impact of domestic violence; unstable relationship with child's father (or mother)

Safe and Supported Living

- Unstable inadequate unaffordable housing

- Access cultural perspectives towards parenting and perinatal care

- Lack of life skills to support independent living

- Poverty's impact on accessing care

Lack of coordinated services for youth
Priority Areas Identified by Young Women Judgment

-In being identified as a child protection risk

- Accessing housing

- $\quad$ Breastfeeding

- Accessing health services

Lack of connection with supports

- Loss of social support network/Isolation

- Not knowing options and resources

Navigating Care/Institutional Barriers

Access to mental health services

Expectations

Permanently labeled

Influence of childhood trauma on parenting

Intimate Partner Violence

Poverty

Table 6: Demographic characteristics of women participating in semi-structured interviews $(\mathrm{N}=10)$

\begin{tabular}{|l|l|l|l|}
\hline Demographic Characteristic & $\%$ & Demographic Characteristic & $\%$ \\
\hline Completed High School & $33 \%$ & CAS involvement in own childhood & $67 \%$ \\
\hline Ethnicity & & Experienced IPV while pregnant or parenting & $78 \%$ \\
\hline $\begin{array}{l}\text { Receives Public Income Assistance } \\
\text { (OntarioWorks, ODSP) }\end{array}$ & $77 \%$ & Experienced abuse of any kind from family & $67 \%$ \\
\hline CAS involvement in pregnancy or parenting & $78 \%$ & $\begin{array}{l}\text { Experienced anxiety or depression while pregnant or } \\
\text { parenting }\end{array}$ & $56 \%$ \\
\hline Youngest Child is in their custody & $89 \%$ & $\begin{array}{l}\text { Accessed mental health services during pregnancy or } \\
\text { post-partum }\end{array}$ & $78 \%$ \\
\hline No longer has custody of earlier child(ren) & $33 \%$ & Used illegal substances while pregnant or parenting & $44 \%$ \\
\hline
\end{tabular}

Table 7: Themes and Concepts Identified in the Literature and by Women around Judgment and Its Consequences in Perinatal Health 


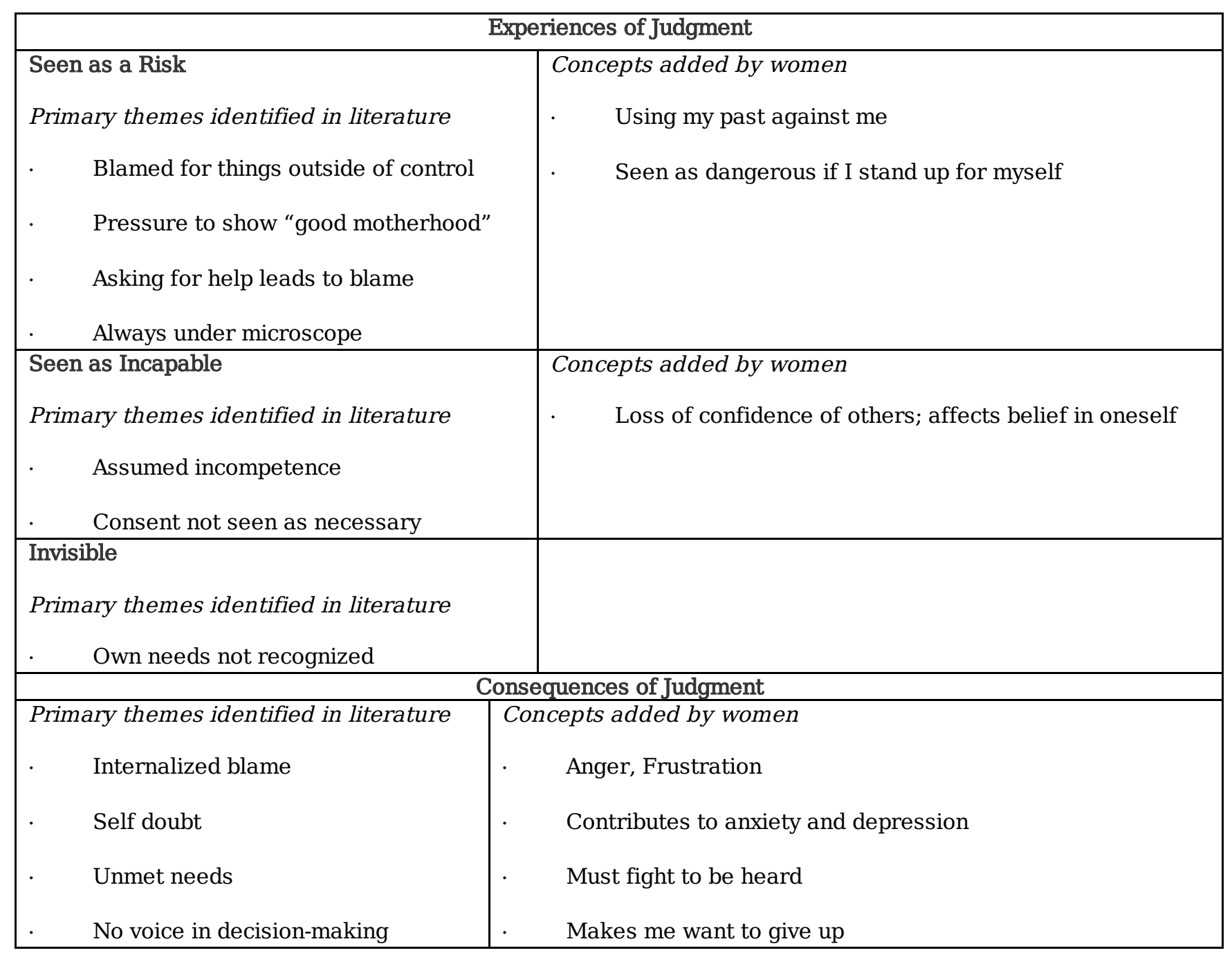

\section{Figures}




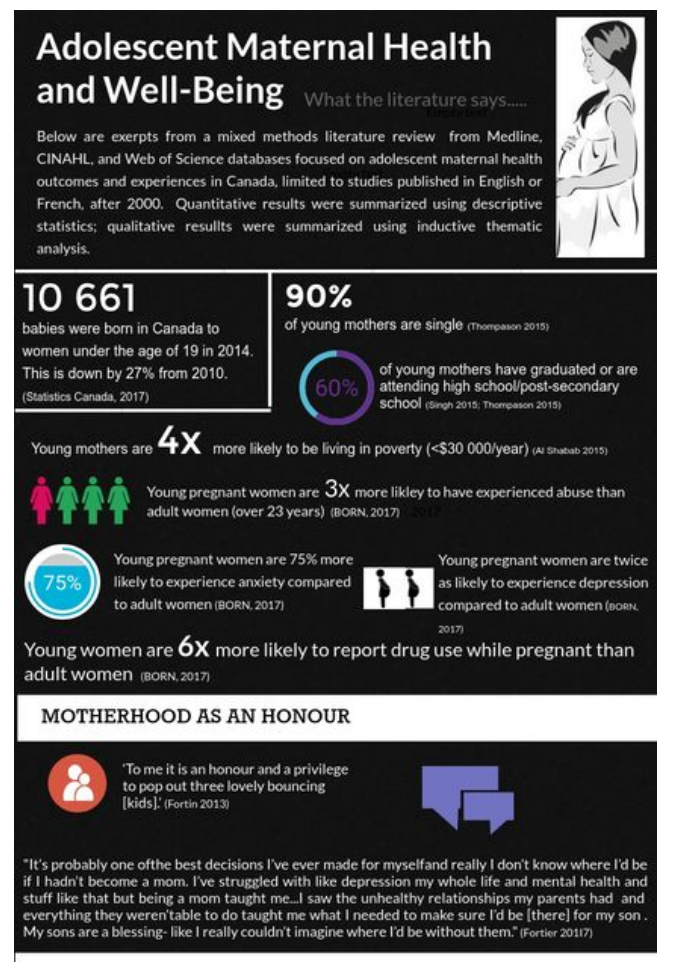

SUPPORT NOT JUDGEMENT

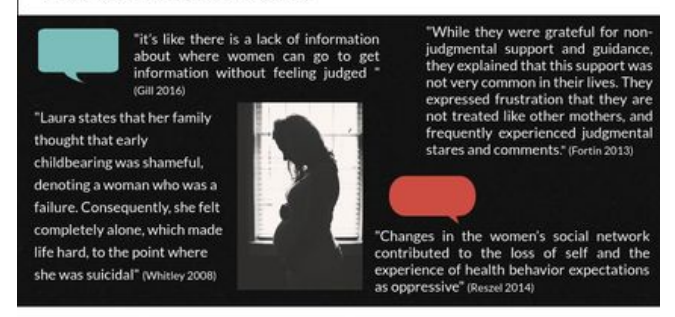

BEING SEEN AS A RISK
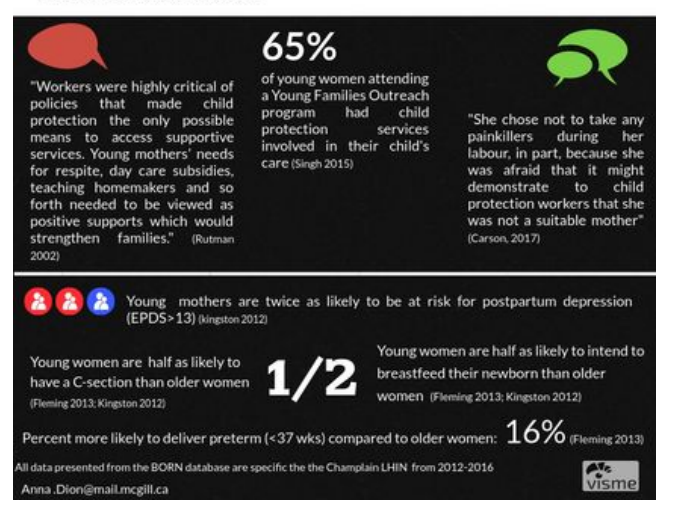

Figure 1

Infographic of Mixed Methods Evidence Synthesis of Experiences and Outcomes of Adolescent Pregnancy in Canada

\section{Supplementary Files}

This is a list of supplementary files associated with this preprint. Click to download.

- AdditionalFile1Datatables.xlsx 